\title{
The Quality Changes and Proteomic Analysis of Cattle Muscle Postmortem during Rigor Mortis
}

\author{
Zhenjiang Ding ${ }^{1,2}$, Qichao Wei ${ }^{1}$, Chunmei Liu ${ }^{1}$, Hong Zhang ${ }^{1}$ and Feng Huang ${ }^{1, *}$ \\ 1 Institute of Food Science and Technology, Chinese Academy of Agricultural Sciences/Key Laboratory of \\ Agro-Products Processing, Ministry of Agriculture and Rural Affairs, Beijing 100193, China; \\ dingzhj18@1zu.edu.cn (Z.D.); weiqichao72@163.com (Q.W.); liuchunmei980119@163.com (C.L.); \\ tfpmlab@163.com (H.Z.) \\ 2 State Key Laboratory of Applied Organic Chemistry and College of Chemistry and Chemical Engineering, \\ Lanzhou University, Lanzhou 730000, China \\ * Correspondence: fhuang226@163.com
}

Citation: Ding, Z.; Wei, Q.; Liu, C.; Zhang, H.; Huang, F. The Quality Changes and Proteomic Analysis of Cattle Muscle Postmortem during Rigor Mortis. Foods 2022, 11, 217. https://doi.org/10.3390/ foods 11020217

Academic Editors: Andrea Garmyn and Juana Fernández-López

Received: 25 November 2021

Accepted: 8 January 2022

Published: 13 January 2022

Publisher's Note: MDPI stays neutral with regard to jurisdictional claims in published maps and institutional affiliations.

Copyright: (C) 2022 by the authors. Licensee MDPI, Basel, Switzerland. This article is an open access article distributed under the terms and conditions of the Creative Commons Attribution (CC BY) license (https:// creativecommons.org/licenses/by/ $4.0 /)$.

\begin{abstract}
Rigor mortis occurs in a relatively early postmortem period and is a complex biochemical process in the conversion of muscle to meat. Understanding the quality changes and biomarkers during rigor mortis can provide a theoretical basis for maintaining and improving meat quality. Herein, a tandem mass tag proteomic method is used to investigate the effects of differentially expressed proteins on the meat quality of cattle Longissimus lumborum muscle postmortem $(0,6$, and $24 \mathrm{~h}$ ). The $\mathrm{pH}$, total sulfhydryl content and sarcomere length decrease significantly during storage. In contrast, meat color values $\left(\mathrm{L}^{*}, \mathrm{a}^{*}\right.$, and $\left.\mathrm{b}^{*}\right)$ and the myofibril fragmentation index increase significantly. Altogether, 147 differentially expressed proteins are identified, most being categorized as metabolic enzymes, mitochondrial proteins, necroptosis and ferroptosis proteins and structural proteins. The results also reveal additional proteins that are potentially involved in rigor mortis, such as cardiac phospholamban, acetyl-coenzyme A acyltransferase, and ankyrin repeat domain 2 . The current results provide proteomic insights into the changes in meat quality during rigor mortis.
\end{abstract}

Keywords: rigor mortis; proteomics; meat quality; bioinformatics; protein biomarkers

\section{Introduction}

Tenderness is an important indicator affecting both meat quality and the purchase intention of consumers. Decreased tenderness (the opposite of tenderness) may be due to background toughness and myofibrillar toughness [1]. Myofibrillar toughness is affected by three phases: the prerigor phase, rigor phase and tenderization phase [2]. Rigor mortis, including delayed phase and rapid phase, is one of the most important and complex biochemical processes in the conversion of muscle to meat. It occurs in a relatively early postmortem (PM) period, resulting in an increase in the toughness of the meat [3]. Even though the blood circulation that supplies oxygen and removes the end products of metabolism is exhausted, the muscles still maintain function and metabolic activity. The sole purpose of anaerobic metabolism of glycogen and high-energy phosphate compounds is to produce adenosine triphosphate (ATP) in the early postmortem muscles. Lactate and hydrogen ions $\left(\mathrm{H}^{+}\right)$are the end products of glycolysis and ATP hydrolysis, respectively. They accumulate in muscles due to the lack of an effective elimination mechanism, leading to a decrease in $\mathrm{pH}$ [4]. This acidification leads to the reduction of water-holding capacity (WHC) and the release of calcium, resulting in the formation of a cross bridge between myosin and actin filaments [5]. In addition, as the glycogen level in the muscle decreases after slaughter, the available energy to maintain the relaxed state of the muscle is also reduced. The combination of these factors results in the onset and development of rigor mortis [6]. Accordingly, it is particularly important to illuminate the complex biochemical mechanism 
of rigor mortis for the preservation of meat after slaughter and the improvement of the profitability of the meat industry.

Proteomics can be defined as the science of studying a subset of all proteins expressed in a certain cell or tissue and has been employed in meat science to explore molecular mechanisms occurring in muscle and affecting meat quality [7]. Proteomic research on beef is the first step to understanding the mechanism of the conversion from muscle to meat and the control of meat quality. The effects of complex proteolysis and the interaction of soluble muscle proteins in aging on meat quality remain major challenges. Finding new protein biomarkers that regulate muscle growth would help scientists test better experimental hypotheses, enabling the meat production industry and consumers to obtain better quality meat [8]. In recent years, scientists have discovered some metabolic enzymes, heat shock proteins (HSPs), oxidative proteins, structural proteins, and proteases related to meat tenderness, color, and WHC as protein biomarkers through proteomics. Metabolic enzymes including glyceraldehyde-3-phosphate dehydrogenase (GAPDH), glycogen phosphorylase (PYGM), pyruvate kinase isozymes M2 isoform (PKM2), adenylate kinase isoenzyme 1 (AK1), fructose-bisphosphate aldolase A isoform (ALDOA), triosephosphate isomerase (TPI1), retinal dehydrogenase 1 (ALDH1A1), malate dehydrogenase (MDH1), and lactoylglutathione lyase (GLO1) are closely correlated with meat color and $\mathrm{pH}$ in $\mathrm{M}$ longissimus lumborum during PM storage [5,9,10]. Similarly, beta-enolase (ENO3), phosphoglucomutase-1 (PGM1), protein-L-isoaspartate O-methyltransferase (PCMT1), and proteasome subunit beta type-2 (PSMB2) are correlated with the $\mathrm{pH}$ and $\mathrm{a}^{*}$ value of meat from semitendinosus by Pearson's correlation analysis [11]. In addition, HSPB1, $\alpha \beta$-crystallin, HSP40, HSP70-8 and HSP90 belong to the family of HSPs that can regulate meat quality $[9,12,13]$. Peroxiredoxin-1 (PRDX1), peroxiredoxin-2 (PRDX2), peroxiredoxin-6 (PRDX6), superoxide dismutase (SOD), and DJ-1 (PARK7) have a key role in the degradation of peroxide and show an increase in oxidative damage in the tender meat group compared to the intermediate and tough meat groups [14]. Structural proteins, including $\alpha$-actin, titin, and myosin heavy chain $(\mathrm{MyHC})$, were of great significance to discriminate the meat color classes [15]. Myosin regulatory light chain 2, keratin, and desmin significantly varied between lowand high-drip groups in the pectoralis major of geese [13]. In the process of meat aging, proteases such as calpains, caspases, lysosomal cathepsins, and proteasomes hydrolyze structural proteins to increase the tenderness of meat [16]. Of the proteins summarized above, it is possible that one protein regulates multiple characteristics of meat quality, and that there are interactions between proteins to regulate meat quality. At present, the application of proteomics is mainly focused on the aging of muscle PM. However, there are few studies focusing on protein changes in rigor mortis, and new protein biomarkers need to be explored to supplement the mechanism of rigor mortis in the process of converting from muscle to meat.

The objective of this study is to investigate protein changes in rigor mortis. Tandem mass tags (TMTs) for quantitation analysis of longissimus lumborum (LL) muscle from cattle with different rigor mortis times were executed. It is hoped that the data will provide a new perspective for the improvement of biochemical mechanisms, discovery of potential protein biomarkers in rigor mortis, and subsequent exploration of the mechanism of meat quality changes.

\section{Materials and Methods}

\subsection{Animals and Muscle Sampling}

Sixty improved cattle (Simmental $\times$ Chinese Luxi yellow cattle, an average living weight of $400 \pm 50 \mathrm{~kg}$, approximately 8 months old) were slaughtered on the same day by a commercial meat processing company (Beijing Zhuochen Animal Husbandry Co., Ltd., Beijing, China) without electrical stimulation in accordance with National Standards of China (GB/T 17237-2008; date: 2018). The protocol was approved by the Animal Care and Ethics Committee of Chinese Academy of Agricultural Sciences (IAS20160616; date: 2016, Beijing, China). The experimental design was summarized in Figure 1. The LL muscle was 
taken immediately from the carcasses within $30 \mathrm{~min}$. Approximately $10 \mathrm{~g}$ muscle (approximately $2 \mathrm{~cm} \times 2 \mathrm{~cm} \times 2 \mathrm{~cm}$, the sample mass for one repetition) was cut and measured for $\mathrm{pH}$ immediately. Another $20 \mathrm{~g}$ of muscle was incubated in sterilized physiological saline solution for 6 and $24 \mathrm{~h}$ at $4{ }^{\circ} \mathrm{C}$ to prevent the growth of microorganisms in the air and facilitate subsequent research. The muscle was subjected to measurements of color, myofibril fragmentation index (MFI), sarcomere length, total sulfhydryl content, and total protein extraction at the sampling time after the measurement of initial $\mathrm{pH}$.

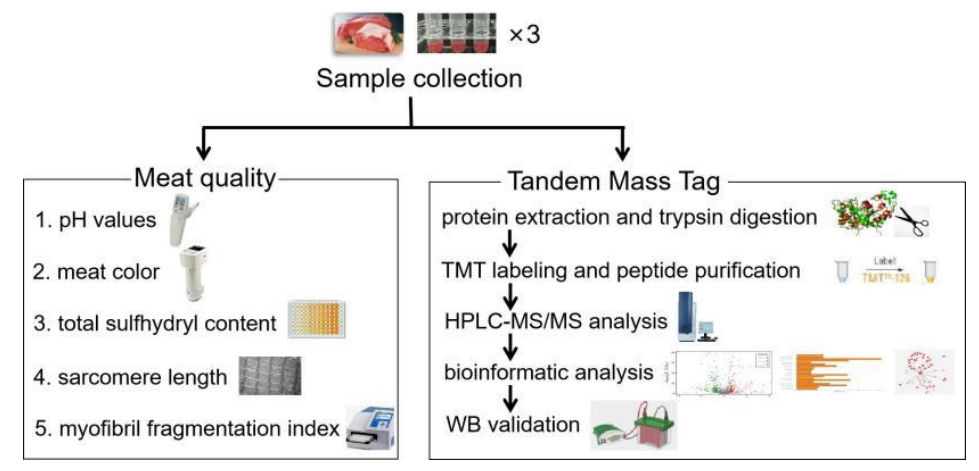

Figure 1. Experimental design and workflow. TMT: tandem mass tags, HPLC-MS/MS: liquidchromatography tandem mass spectrometry, WB: western blot.

\section{2. $p H$ Values}

The $\mathrm{pH}$ values were detected at 0,6 , and $24 \mathrm{~h} \mathrm{PM}$ at 4-6 random locations (repeat one time per $10 \mathrm{~g}$ muscle) with a portable $\mathrm{pH}$ meter equipped with a penetration probe (Testo205 $\mathrm{pH}$ meter, Lenzkirch, Germany). The $\mathrm{pH}$ meter allowed for the automatic detection of buffer solutions and automatic temperature compensation. The probe of the $\mathrm{pH}$ meter was inserted directly into the meat about $1 \mathrm{~cm}$ deep from the meat surface, and the values averaged from 4-6 different points were taken as the final measured $\mathrm{pH}$ values.

\subsection{Meat Color}

The meat color values CIE L* (lightness), $a^{*}$ (redness), and $b^{*}$ (yellowness) were measured at 0, 6, and $24 \mathrm{~h} \mathrm{PM}$ at 4-6 random locations (repeat one time per $10 \mathrm{~g}$ muscle) using a colorimeter (CM-600D, Osaka, Japan). The colorimeter was calibrated with a white tile $(Y=93.6, x=0.3130, y=0.3193$ ) specific to the machine before measuring each sample and set to an illuminant/observer angle of D-65/2 $2^{\circ}$, aperture size of $8 \mathrm{~mm}$, and measurement time of $1 \mathrm{~s}$. The muscle was cut (approximately $2 \mathrm{~cm} \times 2 \mathrm{~cm} \times 2 \mathrm{~cm}$ ) into two pieces from the middle, and meat color values were measured on the freshly cut surface after 30 min of blooming at room temperature.

\subsection{Total Sulfhydryl Content}

Total protein extraction and total sulfhydryl content were measured according to our published work [12]. Total proteins were extracted with phosphate buffer containing $2 \%$ sodium dodecyl sulfate (SDS) and adjusted to a uniform protein concentration

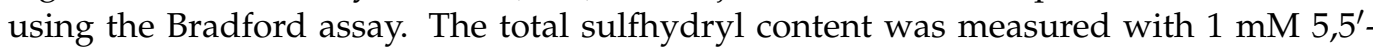
Dithiobis-(2-nitrobenzoic acid) (DTNB) (6 M guanidine hydrochloride, $\mathrm{pH}$ 8.0) by reading the absorbance at $412 \mathrm{~nm}$ with a microplate reader (BioTek, Winooski, VT, USA). The residual total proteins were subjected to proteomics.

\subsection{Sarcomere Length}

Transmission electron microscopy (TEM) was performed according to Zhang et al. [17] with some modifications. The meat samples with a size of $2 \mathrm{~mm} \times 2 \mathrm{~mm} \times 4 \mathrm{~mm}$ were fixed with glutaraldehyde $(2.5 \%)$ for $24 \mathrm{~h}$, washed with phosphate buffer $(\mathrm{pH}=7.2)$, dehydrated by an ethanol gradient $(30 \%, 50 \%, 70 \%, 90 \%$, and $100 \%)$, and exchanged in acetone. The 
samples were then embedded in epoxy resin and sliced using a Leica EM UC6 microtome (Leica, Solms, Germany). Ultrathin sections were stained with uranyl acetate and lead citrate and observed using a New Bio-TEM H-7500 TEM (Hitachi, Tokyo, Japan). The sarcomere length was calculated in the micrographs created using Image-Pro Plus 6.0 software (Media Cybernetics, Rockville, MD, USA).

\subsection{Myofibril Fragmentation Index(MFI)}

The MFI was determined according to Zhang et al. [17] with minor modifications. The minced muscle $(0.5 \mathrm{~g})$, trimmed of visible fat and connective tissue, was homogenized in $5 \mathrm{~mL}$ of ice-cold buffer $\left(100 \mathrm{mM} \mathrm{KCl}, 1 \mathrm{mM} \mathrm{MgCl}_{2}, 20 \mathrm{mM} \mathrm{K}_{2} \mathrm{HPO}\right.$, and $1 \mathrm{mM}$ EDTA; $\mathrm{pH}=7.0$ ). The samples were centrifuged for $15 \mathrm{~min}$ at $3000 \times g$. The precipitate obtained was resuspended in $5 \mathrm{~mL}$ of ice-cold buffer and centrifuged again. The precipitate was then resuspended in buffer and filtered with a polyethylene strainer ( 20 mesh). The protein concentration of the filtrate was measured by the biuret method, and the concentration was then adjusted to $0.5 \pm 0.05 \mathrm{mg} / \mathrm{mL}$ with buffer. The absorbance at $540 \mathrm{~nm}$ was measured and the result was multiplied by 200 to obtain the MFI value.

\subsection{Trypsin Digestion and Tandem Mass Tag (TMT) Labeling}

Each sample (approximately $100 \mu \mathrm{g}$ of total proteins) was precipitated with $4 \mathrm{vol}(\mathrm{v} / \mathrm{v})$ of ice-cold acetone, and the precipitate was resuspended in reducing buffer ( $8 \mathrm{M}$ urea, $30 \mathrm{mM}$ HEPES, $1 \mathrm{mM}$ PMSF, $2 \mathrm{mM}$ EDTA, $10 \mathrm{mM}$ DTT) and incubated at $56{ }^{\circ} \mathrm{C}$ for $1 \mathrm{~h}$. Then, iodoacetamide $(55 \mathrm{mM})$ was added to alkylate in the dark for $45 \mathrm{~min}$. The mixture was centrifuged in a $10 \mathrm{kDa}$ ultrafiltration tube for $20 \mathrm{~min}$ at $12,000 \mathrm{rpm}$ and $4{ }^{\circ} \mathrm{C}$, and the filter was washed twice with $200 \mu \mathrm{L}$ of $50 \mathrm{mM}$ TEAB and centrifuged at 12,000 rpm for $20 \mathrm{~min}$. The proteins were digested with $3 \mu \mathrm{g}$ trypsin $/ 100 \mu \mathrm{g}$ proteins overnight at $37^{\circ} \mathrm{C}$. The resulting peptides were lyophilized and then further reconstituted in $30 \mu \mathrm{L} \mathrm{TEAB}$ for labeling. Each TMT reagent was dissolved in $70 \mu \mathrm{L}$ of isopropanol mixed with the peptide solution [18].

\subsection{Peptide Purification and HPLC-MS/MS Analysis}

The labeled peptide was diluted with solution A $(0.1 \%$ formic acid, $2 \%$ ACN, $98 \%$ water) and preseparated with solution B (0.1\% formic acid, $2 \%$ water, $98 \% \mathrm{ACN})$, and different components were collected at different times. The collected peptides were desalted and purified by C18 column according to the manufacturer's instructions. Desalted peptide mixtures were loaded onto an Acclaim PepMap C18 reversed-phase column $(75 \mu \mathrm{m} \times 2 \mathrm{~cm}$, $3 \mu \mathrm{m})$ and separated with a reversed-phase C18 column $(75 \mu \mathrm{m} \times 10 \mathrm{~cm}, 5 \mu \mathrm{m})$ mounted on a Dionex UltiMate 3000 Nano LC system. Peptides were eluted using a gradient of solution B $(5 \%, 5 \%, 30 \%, 60 \%, 80 \%, 100 \%)$ at a flow rate of $300 \mathrm{~nL} / \mathrm{min}$ combined with a $\mathrm{Q}$ Exactive mass spectrometer (Thermo Fisher Scientific, MA, USA). The eluates were directly entered into the Q Exactive MS (Thermo Fisher Scientific, Waltham, MA, USA) in positive ion mode and data-dependent manner with a full MS scan from 350-2000 m/z, full scan resolution at 70,000, and MS/MS scan resolution at 17,500. An MS/MS scan with minimum signal threshold $1 \times 10^{5}$, isolation width at 2 Da was completed. The MS/MS acquisition mode was higher collision energy dissociation (HCD). To optimize the MS/MS acquisition efficiency of HCD, normalized collision energy (NCE) was systemically examined with a stepping of $20 \%$.

\subsection{Data Process and Bioinformatic Analysis}

The obtained MS/MS data were analyzed using Proteome Discoverer 1.4 and searched using Mascot version 2.3.0. Information for the UniProt database and the reversed database was collected as follows: database, UniProt-bovine (ID: 9913); peptide mass tolerance, 15 ppm; MS/MS tolerance, $20 \mathrm{mmu}$; max missed cleavages, 1; fixed modification, carbamidomethyl (C); variable modification, oxidation (M), Gln $\rightarrow$ pyro-Glu (N-term Q), TMT 6 plex $(\mathrm{K})$, TMT 6 plex (N-term); protein ratio type, median; minimum peptides, 1; normal- 
ization method, median. Based on the identified proteins, ANOVA was applied to screen out the differences in protein expression among the three groups $(0,6$ and $24 \mathrm{~h} \mathrm{PM})$ with $p<0.05$ and fold change $>1.5$ or $<2 / 3$. Then, RStudio and Cytoscape were used to perform bioinformatic analysis of the obtained differential proteins, including gene ontology (GO, http:/ / geneontology.org/, accessed on 10 July 2021), the Kyoto Encyclopedia of Genes and Genomes (KEGG, http:/ / www.genome.jp/kegg/, accessed on 10 July 2021) pathway, and the protein-protein interaction (PPI, https://string-db.org/, accessed on 10 July 2021) network [18]. The significance level of the protein enrichment of a given GO term was tested by Fisher's exact test. The significance level of protein enrichment in each pathway by Fisher's exact test in the unit of the KEGG pathway was obtained to identify the significant metabolic and signal transduction pathways. Regarding PPI, default settings were used, i.e., medium confidence of 0.4 and 4 criteria for linkage: co-occurrence, experimental evidence, existing databases, and text mining.

\subsection{SDS-PAGE and Western Blotting}

To further check the changes in protein expression levels, SDS-PAGE and western blotting analysis, as well as additional quantification, were performed according to our published work [12]. The expression levels of pyruvate kinase (PKM), troponin T (TNNT1), cytochrome c oxidase subunit 5A (COX5A), mitochondrial fission 1 protein (FIS1), cytochrome c oxidase subunit 4 isoform 1 (COX4I1), and NADH dehydrogenase [ubiquinone] 1 beta subcomplex subunit 11 (NDUFB11) were detected through SDS-PAGE and western blotting. Total proteins were extracted according to our previous study [12]. The minced muscle was homogenized in $1.5 \mathrm{~mL}$ of ice-cold $2 \%$ SDS in $10 \mathrm{mM}$ phosphate buffer (pH 7.2) and quantified using the Bradford assay. $12.5 \%$ polyacrylamide separating gels and $4.5 \%$ polyacrylamide stacking gels were used, and $40 \mu \mathrm{g}$ samples were loaded per well. The gels were electrophoresed on the Bio-Rad Mini-PROTEAN II system (Bio-Rad Laboratories, Hercules, CA, USA) at a voltage of $80 \mathrm{~V}$ for $0.5 \mathrm{~h}$, followed by $120 \mathrm{~V}$ until the indicator line reached the bottom of the gel. After electrophoresis, proteins were transferred to a membrane at $200 \mathrm{~mA}$ and $4{ }^{\circ} \mathrm{C}$ for $60 \mathrm{~min}$ and then blocked with $5 \%(w / v)$ nonfat dry milk in TBST (20 mM Tris, $137 \mathrm{mM} \mathrm{NaCl}, 5 \mathrm{mM} \mathrm{KCl}$, and $0.05 \%(v / v)$ Tween 20), and the membrane was then incubated with anti-PKM2 (D220008, Sangon Biotech, Shanghai, China, 1:1000), anti-troponin T (clone JLT-12, Sigma, Saint Louis, MO, USA, 1:2000), anti-COX5A (ab110262, Abcam, Cambridge, UK, 1:2000), anti-FIS1 (D222377, Sangon Biotech, Shanghai, China, 1:1000), anti-COX4I1 (ab16056, Abcam, Cambridge, UK, 1:2000), and anti-NDUFB11 (D223630, Sangon Biotech, Shanghai, China, 1:1000) according to the manufacturers' instructions. The membranes were incubated with secondary antibodies (A9044, Sigma, Saint Louis, MO, USA, 1:4000) after washing four times with TBST buffer, and then the proteins were visualized by immobilon western chemilum HRP (ECL) substrate (Bio-Rad, Hercules, CA, USA) after washing four times with TBST buffer. The membranes were imaged by ChemiDocTMMP Imaging System (Bio-Rad, Hercules, CA, USA).

\subsection{Statistical Analysis}

The significant differences among different PM storage times were analyzed by the SPSS statistical software package (17.0, IBM, Chicago, IL, USA). LSD and Duncan's multiple range test were used to compare individual mean differences $(p<0.05)$. The data in all experiments were expressed as the mean \pm SD (standard deviation) from 4-6 replicates. The densities of targeted bands were analyzed using Quantity One software (Bio-Rad, Hercules, CA, USA). The protein densities at $0 \mathrm{~h}$ were used as the control when comparing the differentially expressed proteins at $0 \mathrm{~h}$ vs. $6 \mathrm{~h}$ PM. Protein densities of $6 \mathrm{~h}$ were used as the control when comparing the differentially expressed proteins of $6 \mathrm{~h}$ vs. $24 \mathrm{~h}$ PM. Statistical differences between the two groups were determined by Student's t-test. 


\section{Results and Discussion}

\section{1. $\mathrm{pH}$ and Meat Color}

The $\mathrm{pH}$ values of skeletal muscle during rigor mortis are shown in Table 1 . The $\mathrm{pH}$ values significantly decreased within $24 \mathrm{~h}$ PM. This may be due to the accumulation of lactate acid and $\mathrm{H}^{+}$, which are the final products of glycolysis and ATP hydrolysis, respectively [4]. The rapid decrease in the $\mathrm{pH}$ values PM affected not only the onset and development of rigor mortis [19] but also protein degradation and endogenous enzyme activity during aging [20], which in turn regulated meat tenderness.

Table 1. $\mathrm{pH}$ and meat color of Longissimus lumborum muscles during postmortem storage.

\begin{tabular}{ccccc}
\hline & $\mathbf{p H}$ & $\mathbf{L}^{*}$ & $\mathbf{a}^{*}$ & $\mathbf{b}^{*}$ \\
\hline $0 \mathrm{~h}$ & $6.541 \pm 0.185^{\mathrm{a}}$ & $29.066 \pm 1.299^{\mathrm{a}}$ & $8.650 \pm 1.103^{\mathrm{a}}$ & $4.864 \pm 0.291^{\mathrm{a}}$ \\
$6 \mathrm{~h}$ & $5.530 \pm 0.164^{\mathrm{b}}$ & $29.744 \pm 1.448^{\mathrm{a}}$ & $11.294 \pm 0.865^{\mathrm{b}}$ & $7.156 \pm 1.052^{\mathrm{b}}$ \\
$24 \mathrm{~h}$ & $5.224 \pm 0.015^{\mathrm{c}}$ & $34.429 \pm 1.643^{\mathrm{b}}$ & $13.997 \pm 2.040^{\mathrm{c}}$ & $9.888 \pm 1.429^{\mathrm{c}}$
\end{tabular}

$\mathrm{L}^{*}, \mathrm{a}^{*}$, and $\mathrm{b}^{*}$ represent lightness, redness, and yellowness, respectively; different letters ${ }^{\mathrm{a}-\mathrm{c}}$ ) in the same column indicate significant differences at different postmortem storage times $(p<0.05)$. The data were expressed as the mean \pm SD.

Meat color is the most intuitive indicator for consumers to evaluate meat product quality. The $\mathrm{L}^{*}$ value of skeletal muscle increased significantly from 6 to $24 \mathrm{~h}$, while there was no significant difference from 0 to $6 \mathrm{~h}$ (Table 1 ). The $\mathrm{a}^{*}$ value of skeletal muscle continued to increase from 0 to $24 \mathrm{~h}$ after slaughter $(p<0.05)$ (Table 1$)$. The $\mathrm{b}^{*}$ value increased significantly from 0 to $24 \mathrm{~h}$ (Table 1 ). The sarcoplasmic protein degeneration and myofibril shrinkage that occurred in the early stage of PM increased the scattering of meat and caused meat to become lighter. In addition, myoglobin was oxygenated to oxymyoglobin when atmospheric oxygen permeated the meat surface, resulting in the meat appearing bright red [21].

\subsection{Total Sulfhydryl Content, Sarcomere Length and MFI}

As an important reactive group of proteins or small biological molecules in cells, sulfhydryl groups are oxidized to form disulfide bonds, sulfonic acid, and other oxidative derivatives by oxidizing agents produced during meat storage, resulting in meat quality deterioration [12]. Therefore, the oxidation state has an important biological function for molecular activity. Total sulfhydryl content was measured found to gradually decrease during rigor mortis (Table 2). Total sulfhydryl content is a good indicator of protein oxidation level. A study of refrigerated turkey meat revealed similarly reduced sulfhydryl content during storage [14].

Table 2. Total sulfhydryl content, MFI (myofibril fragmentation index), and sarcomere length of Longissimus lumborum muscles during postmortem storage.

\begin{tabular}{cccc}
\hline & Total Sulfhydryl Content (\%) & MFI & Sarcomere Length $(\mu \mathrm{m})$ \\
\hline $0 \mathrm{~h}$ & $100.00 \pm 5.136^{\mathrm{a}}$ & $52.233 \pm 0.463^{\mathrm{a}}$ & $1.278 \pm 0.013^{\mathrm{a}}$ \\
$6 \mathrm{~h}$ & $80.058 \pm 2.362^{\mathrm{b}}$ & $56.333 \pm 0.689^{\mathrm{b}}$ & $1.164 \pm 0.020^{\mathrm{b}}$ \\
$24 \mathrm{~h}$ & $67.928 \pm 5.136^{\mathrm{c}}$ & $61.000 \pm 0.253^{\mathrm{c}}$ & $1.054 \pm 0.035^{\mathrm{c}}$ \\
\hline
\end{tabular}

Different letters $\left.{ }^{(\mathrm{a}-\mathrm{c}}\right)$ in the same column indicate significant differences at different postmortem storage times $(p<0.05)$. The data were expressed as the mean \pm SD.

Proteolysis after slaughter can lead to ultrastructural changes of myofibrils, including Z-lines, M-lines, and A-bands, which are related to the tenderization of muscle into meat [22]. TEM images of myofibrils PM are shown in Figure 2. The apparent Z-lines and $\mathrm{M}$-lines were clearly perceived, and the sarcomere structure was neatly arranged in the $0 \mathrm{~h}$ sample. Some misalignment of the sarcomeres was perceived in the $6 \mathrm{~h}$ PM samples. The ultrastructure of the muscle at $24 \mathrm{~h}$ after slaughter showed obvious changes compared with 
$0 \mathrm{~h}$, mainly reflected in the obscured Z-lines and M-lines and the complete misalignment of the sarcomere structure. The destruction of the sarcomere structure may be caused by changes in the interaction of F-actin, actomyosin, and tropomyosin [23]. In addition, sarcomere length, determined from the TEM images, was shown in Table 2. The sarcomere length of skeletal muscle decreased significantly from 0 to $24 \mathrm{~h} \mathrm{PM}$. Similar results were reported by Wang et al. [24], who concluded that the sarcomere length of the Longissimus lumborum, semimembranosus and Psoas major muscles evidently decreased from 0.5 to $24 \mathrm{~h}$ PM. The sarcomere length of breast muscles from reared broilers decreased significantly until $3 \mathrm{~h}$ PM [25]. This may be caused by the formation of cross-links between myosin S-1 heads and actin, resulting in actomyosin in rigor mortis [26]. Additionally, the decrease in sarcomere length may also be related to cold shortening caused by diminished functioning of the calcium pumps in the sarcoplasmic reticulum at low temperatures [27].

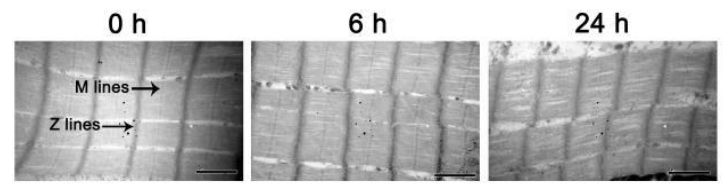

Figure 2. Transmission electron microscopy (TEM) images of longissimus lumborum muscles during postmortem storage.

MFI is a useful index that reflects the degree of proteolysis, thereby characterizing tenderness, indicating I-band breakage and intermyofibril linkages [17]. As shown in Table 2, MFI increased significantly with the increase of time PM, which is consistent with the previous result that MFI of meat from breast and thigh increased significantly $12 \mathrm{~h}$ PM [17]. The overlap of myosin filaments from one sarcomere with actin filaments to the next may form a continuously linked actomyosin after formation of rigor crossbridges. At very short sarcomere lengths, myofibrils within a sarcomere can be ruptured by the shortening of neighboring sarcomeres [26].

\subsection{Bioinformatics Analysis of the Differential Proteins and WB Validation}

Proteome analysis based on tandem mass tags (TMTs) has been widely used in meat science due to its proteome coverage, accurate quantification, and high technical reproducibility [5]. According to TMT analysis, 83 differentially expressed proteins were identified between $6 \mathrm{~h}$ and $0 \mathrm{~h} \mathrm{PM}$, including 36 upregulated and 47 downregulated proteins, which are summarized in Table S1. In total, 71 proteins were determined to be different in abundance between $24 \mathrm{~h}$ and $6 \mathrm{~h}$ PM, of which 12 proteins were upregulated and 59 were downregulated in the $24 \mathrm{~h}$ PM group, as summarized in Table S2.

GO annotation, consisting of biological processes, cellular components, and molecular functions, was performed to obtain information about the mechanism of rigor mortis. The top 10 specific items of the three categories of differential proteins between $6 \mathrm{~h}$ and $0 \mathrm{~h} \mathrm{PM}$ are shown in Table 3. For biological processes, ADP (adenosine diphosphate) metabolic process (GO:0046031), ATP generation from ADP (GO:0006757), nucleoside diphosphate metabolic process (GO:0009185), ribonucleoside diphosphate metabolic process (GO:0009185), pyruvate biosynthetic process (GO:0042866), and other biological processes related to metabolism were significantly enriched. Cellular components were enriched in contractile fiber (GO:0043292), I band (GO:0031674), myofibril (GO:0030016), and sarcomere (GO:0030017), which are related to myofibrillar proteins and sarcomere structure. For molecular function, the major classes of proteins were magnesium ion binding (GO:0000287), superoxide dismutase activity (GO:0004784), and transferase activity (GO:0016740). From each of the three categories of differential proteins, the 10 mostobserved proteins between $24 \mathrm{~h}$ and $6 \mathrm{~h} \mathrm{PM}$ are shown in Table 4. For biological processes, drug transport (GO:0015893), establishment of localization (GO:0051234), ion transport (GO:0006811) and other biological processes related to transport were significantly enriched. Cellular components were mainly enriched in various membrane parts, such as the integral 
component of membrane (GO:0016021), intrinsic component of membrane (GO:0031224), mitochondrial membrane (GO:0031966), and organelle membrane (GO:0031090). For molecular function, the major classes of these proteins were active transmembrane transporter activity (GO:0022804), inorganic molecular entity transmembrane transporter activity (GO:0015318), and ion transmembrane transporter activity (GO:0015075). These GO analyses of the differentially expressed proteins of $6 \mathrm{~h}$ vs. $0 \mathrm{~h}$ and $24 \mathrm{~h}$ vs. $6 \mathrm{~h}$ are displayed in Tables S3 and S4, respectively.

KEGG pathway enrichment was performed to clarify the biological pathways involved in the differentially expressed proteins during rigor mortis. The top 20 specific differential proteins between $6 \mathrm{~h}$ and $0 \mathrm{~h}$ PM are shown in Table 5 , including biosynthesis of amino acids (map01230), carbon metabolism, glycolysis/gluconeogenesis (map00010), insulin signaling pathway (map04910), and pyruvate metabolism (map00620). The top 13 significantly enriched pathways of differential proteins between $24 \mathrm{~h}$ and $6 \mathrm{~h}$ PM were selected (Table 6), including the calcium signaling pathway (map04020), cGMP-PKG signaling pathway (map04022), necroptosis (map04217), and oxidative phosphorylation (map00190). These KEGG pathway analyses of the differentially expressed proteins of $6 \mathrm{~h}$ vs. $0 \mathrm{~h}$ and $24 \mathrm{~h}$ vs. $6 \mathrm{~h}$ are displayed in Tables S5 and S6, respectively. These biological processes may involve the onset and development of rigor mortis.

Table 3. Gene ontology classification results of differentially expressed proteins of $6 \mathrm{~h}$ vs. $0 \mathrm{~h} \mathrm{PM}$.

\begin{tabular}{|c|c|c|c|}
\hline & Term & Description & $p$ Value \\
\hline \multirow{10}{*}{ 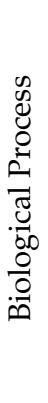 } & GO:0046031 & ADP metabolic process & $6.10 \times 10^{-9}$ \\
\hline & GO:0006757 & ATP generation from ADP & $3.02 \times 10^{-8}$ \\
\hline & GO:0009132 & Nucleoside diphosphate metabolic process & $1.02 \times 10^{-8}$ \\
\hline & GO:0006165 & Nucleoside diphosphate phosphorylation & $2.03 \times 10^{-9}$ \\
\hline & GO:0046939 & Nucleotide phosphorylation & $2.03 \times 10^{-9}$ \\
\hline & GO:0046434 & Organophosphate catabolic process & $3.67 \times 10^{-8}$ \\
\hline & GO:0009135 & Purine nucleoside diphosphate metabolic process & $6.10 \times 10^{-9}$ \\
\hline & GO:0009179 & Purine ribonucleoside diphosphate metabolic process & $6.10 \times 10^{-9}$ \\
\hline & GO:0042866 & Pyruvate biosynthetic process & $3.02 \times 10^{-8}$ \\
\hline & GO:0009185 & Ribonucleoside diphosphate metabolic process & $6.10 \times 10^{-9}$ \\
\hline \multirow{10}{*}{ 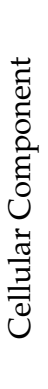 } & GO:0005903 & Brush border & 0.043 \\
\hline & GO:1990584 & Cardiac troponin complex & 0.037 \\
\hline & GO:0043292 & Contractile fiber & 0.009 \\
\hline & GO:0044449 & Contractile fiber part & 0.008 \\
\hline & GO:0098850 & Extrinsic component of synaptic vesicle membrane & 0.020 \\
\hline & GO:0097452 & GAIT complex & 0.037 \\
\hline & GO:0031674 & I band & 0.037 \\
\hline & GO:0030016 & Myofibril & 0.009 \\
\hline & GO:0030017 & Sarcomere & 0.006 \\
\hline & GO:0005861 & Troponin complex & 0.015 \\
\hline \multirow{10}{*}{ 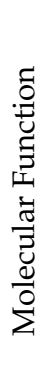 } & GO:0051373 & FATZ binding & $4.58 \times 10^{-5}$ \\
\hline & GO:0016866 & Intramolecular transferase activity & $2.14 \times 10^{-4}$ \\
\hline & GO:0016868 & Intramolecular transferase activity, phosphotransferases & 0.002 \\
\hline & GO:0000287 & Magnesium ion binding & 0.006 \\
\hline & GO:0004784 & Superoxide dismutase activity & 0.007 \\
\hline & GO:0016532 & Superoxide dismutase copper chaperone activity & 0.007 \\
\hline & GO:0031433 & Telethonin binding & 0.002 \\
\hline & GO:0016740 & Transferase activity & $9.75 \times 10^{-4}$ \\
\hline & GO:0016769 & Transferase activity, transferring nitrogenous groups & 0.001 \\
\hline & GO:0009041 & Uridylate kinase activity & 0.007 \\
\hline
\end{tabular}


Table 4. Gene ontology classification results of differentially expressed proteins of $24 \mathrm{~h}$ vs. $6 \mathrm{~h}$ PM.

\begin{tabular}{|c|c|c|c|}
\hline & Term & Description & $p$ Value \\
\hline \multirow{10}{*}{ 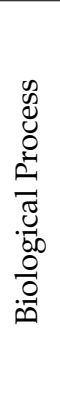 } & GO:0098656 & Anion transmembrane transport & $2.42 \times 10^{-5}$ \\
\hline & GO:0006820 & Anion transport & $9.35 \times 10^{-5}$ \\
\hline & GO:1905039 & Carboxylic acid transmembrane transport & $3.52 \times 10^{-4}$ \\
\hline & GO:0015893 & Drug transport & $9.31 \times 10^{-6}$ \\
\hline & GO:0051234 & Establishment of localization & $3.68 \times 10^{-4}$ \\
\hline & GO:0034220 & Ion transmembrane transport & $6.68 \times 10^{-4}$ \\
\hline & GO:0006811 & Ion transport & $2.37 \times 10^{-5}$ \\
\hline & GO:0021675 & Nerve development & $3.52 \times 10^{-4}$ \\
\hline & GO:1903825 & Organic acid transmembrane transport & $3.52 \times 10^{-4}$ \\
\hline & GO:0006810 & Transport & $3.42 \times 10^{-4}$ \\
\hline \multirow{10}{*}{ 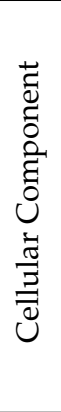 } & GO:0031975 & Envelope & $4.82 \times 10^{-4}$ \\
\hline & GO:0016021 & Integral component of membrane & $3.94 \times 10^{-10}$ \\
\hline & GO:0031301 & Integral component of organelle membrane & $5.38 \times 10^{-4}$ \\
\hline & GO:0031224 & Intrinsic component of membrane & $5.74 \times 10^{-10}$ \\
\hline & GO:0098573 & Intrinsic component of mitochondrial membrane & $5.38 \times 10^{-4}$ \\
\hline & GO:0044425 & Membrane part & $1.88 \times 10^{-4}$ \\
\hline & GO:0005740 & Mitochondrial envelope & $3.47 \times 10^{-4}$ \\
\hline & GO:0031966 & Mitochondrial membrane & $3.52 \times 10^{-4}$ \\
\hline & GO:0031967 & Organelle envelope & $4.82 \times 10^{-4}$ \\
\hline & GO:0031090 & Organelle membrane & $1.49 \times 10^{-4}$ \\
\hline \multirow{10}{*}{ 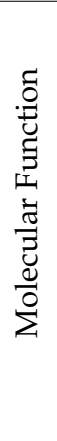 } & GO:0022804 & Active transmembrane transporter activity & $6.62 \times 10^{-5}$ \\
\hline & GO:0008509 & Anion transmembrane transporter activity & $7.26 \times 10^{-7}$ \\
\hline & GO:0046943 & Carboxylic acid transmembrane transporter activity & $3.52 \times 10^{-4}$ \\
\hline & GO:0015238 & Drug transmembrane transporter activity & $3.52 \times 10^{-4}$ \\
\hline & GO:0015318 & $\begin{array}{l}\text { Inorganic molecular entity transmembrane transporter } \\
\text { activity }\end{array}$ & $8.75 \times 10^{-6}$ \\
\hline & GO:0015075 & Ion transmembrane transporter activity & $8.75 \times 10^{-6}$ \\
\hline & GO:0008514 & Organic anion transmembrane transporter activity & $2.42 \times 10^{-5}$ \\
\hline & GO:0015291 & Secondary active transmembrane transporter activity & $2.42 \times 10^{-5}$ \\
\hline & GO:0022857 & Transmembrane transporter activity & $3.15 \times 10^{-6}$ \\
\hline & GO:0005215 & Transporter activity & $6.38 \times 10^{-6}$ \\
\hline
\end{tabular}

Table 5. KEGG pathway enrichment of differentially expressed proteins of $6 \mathrm{~h}$ vs. $0 \mathrm{~h}$ PM.

\begin{tabular}{lll}
\hline Pathway & Pathway Name & $p$ Value \\
\hline map00220 & Arginine biosynthesis & 0.037 \\
map01230 & Biosynthesis of amino acids & $2.39 \times 10^{-5}$ \\
map01200 & Carbon metabolism & $7.47 \times 10^{-6}$ \\
map05204 & Chemical carcinogenesis & 0.005 \\
map00270 & Cysteine and methionine metabolism & 0.006 \\
map00982 & Drug metabolism-cytochrome P450 & 0.009 \\
map00051 & Fructose and mannose metabolism & 0.009 \\
map00052 & Galactose metabolism & 0.037 \\
map00480 & Glutathione metabolism & 0.006 \\
map00010 & Glycolysis/Gluconeogenesis & $7.77 \times 10^{-9}$ \\
map04910 & Insulin signaling pathway & 0.029 \\
map04213 & Longevity regulating pathway-multiple species & 0.009 \\
map01100 & Metabolic pathways & $3.48 \times 10^{-7}$ \\
map00980 & Metabolism of xenobiotics by cytochrome P450 & 0.015 \\
map00030 & Pentose phosphate pathway & 0.004 \\
map04146 & Peroxisome & 0.023 \\
map00360 & Phenylalanine metabolism & 0.037 \\
map00620 & Pyruvate metabolism & 0.001 \\
map00500 & Starch and sucrose metabolism & 0.032 \\
map00750 & Vitamin B6 metabolism & 0.007 \\
\hline
\end{tabular}


Table 6. KEGG pathway enrichment of differentially expressed proteins of $24 \mathrm{~h}$ vs. $6 \mathrm{~h}$ PM.

\begin{tabular}{lll}
\hline Pathway & Pathway Name & $p$ Value \\
\hline map05010 & Alzheimer's disease & 0.013 \\
map04020 & Calcium signaling pathway & $8.00 \times 10^{-5}$ \\
map04022 & CGMP-PKG signaling pathway & $4.70 \times 10^{-4}$ \\
map05166 & HTLV-I infection & 0.002 \\
map05016 & Huntington's disease & 0.002 \\
map04657 & IL-17 signaling pathway & 0.044 \\
map04211 & Longevity regulating pathway & 0.044 \\
map05144 & Malaria & 0.027 \\
map04217 & Necroptosis & 0.039 \\
map00190 & Oxidative phosphorylation & 0.006 \\
map05012 & Parkinson's disease & $6.80 \times 10^{-5}$ \\
map04742 & Taste transduction & 0.005 \\
map00130 & Ubiquinone and other terpenoid-quinone biosynthesis & 0.014 \\
\hline
\end{tabular}

The PPI network of the differentially expressed proteins of $6 \mathrm{~h}$ vs. $0 \mathrm{~h}$ and $24 \mathrm{~h}$ vs. $6 \mathrm{~h}$ was constructed and shown in Figure 3A,B, respectively. The proteins at $6 \mathrm{~h}$ vs. $0 \mathrm{~h}$ that were pyruvate kinase (PKM), dihydrolipoyl dehydrogenase (DLD), phosphoglycerate mutase 2 (PGAM2), fructose-1,6-bisphosphatase isozyme 2 (FBP2), phosphoglycerate kinase 1 (PGK1), glucose-6-phosphate isomerase (GPI), beta-enolase (ENO3), triosephosphate isomerase (TPI1), lactoylglutathione lyase (GLO1), and malate dehydrogenase (MDH1/2). These proteins were implicated in glycolysis/gluconeogenesis, pyruvate metabolism, carbon metabolism, citrate cycle, and oxidative phosphorylation. The proteins at $24 \mathrm{~h}$ vs. $6 \mathrm{~h}$ were cardiac phospholamban (PLN), ryanodine receptor 1 (RYR1), calcium-transporting ATPase (ATP2A2), cAMP-dependent protein kinase catalytic subunit alpha (PRKACA), voltage-dependent anion-selective channel protein 2 (VDAC2), sarcoplasmic/endoplasmic reticulum calcium ATPase 1 (ATP2A1), voltage-dependent anion-selective channel protein 3 (VDAC3), myosin heavy chain 6 (MYH6), myosin regulatory light chain 2 (MYL2), and protein kinase AMP-activated non-catalytic subunit gamma 2 (PRKAG2). These proteins were implicated in the calcium signaling pathway, cGMP-PKG signaling pathway, ferroptosis, necroptosis, tight junction, cardiac muscle contraction, vascular smooth muscle contraction, and focal adhesion.

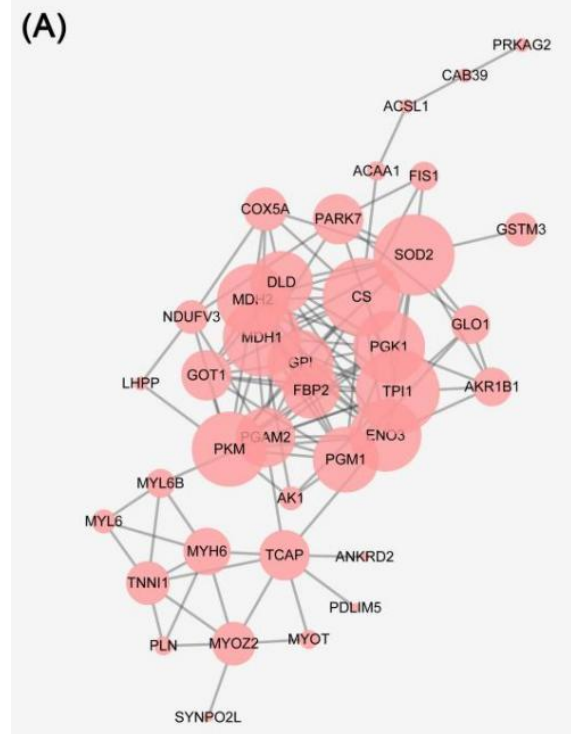

(B)

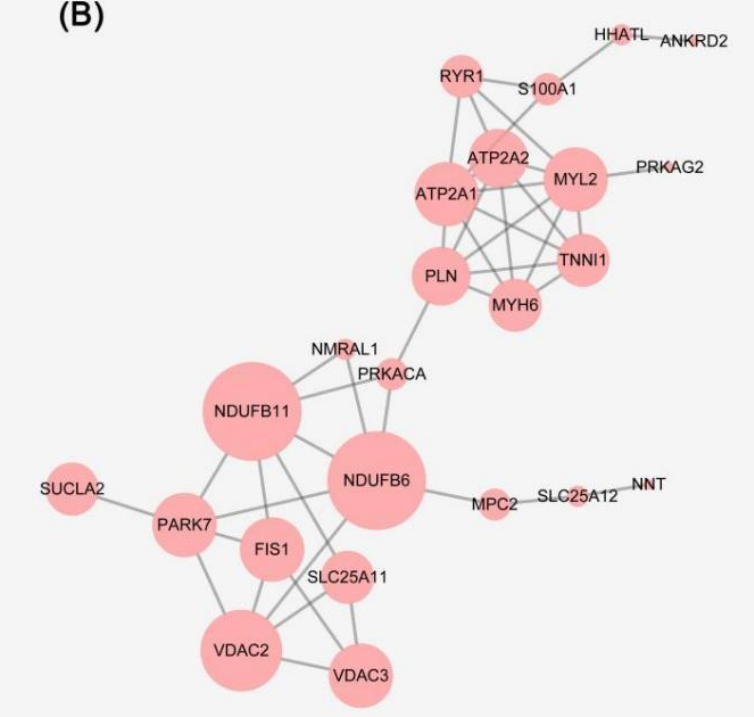

Figure 3. (A) Protein-protein interaction networks of differentially expressed proteins of $6 \mathrm{~h}$ vs. $0 \mathrm{~h}$ PM. (B) Protein-protein interaction networks of differentially expressed proteins of $24 \mathrm{~h}$ vs. $6 \mathrm{~h}$ PM. 
Several different upregulated and downregulated proteins were selected to validate the TMT results by western blotting, including pyruvate kinase (PKM), troponin T (TNNT1), cytochrome c oxidase subunit 5A (COX5A), mitochondrial fission 1 protein (FIS1), cytochrome c oxidase subunit 4 isoform 1 (COX4I1), and NADH dehydrogenase [ubiquinone] 1 beta subcomplex subunit 11 (NDUFB11). As shown in Figure 4 and Table 7, the changes in these protein levels were consistent with the results of TMT analysis, indicating that the TMT results in this study are reliable.
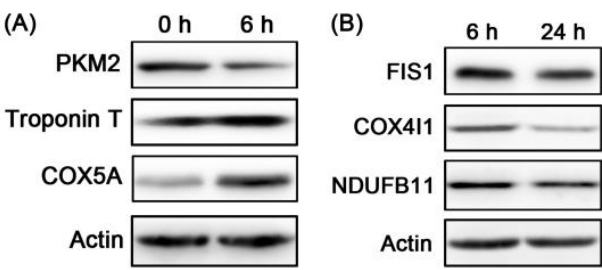

Figure 4. (A) Validation of the differentially expressed proteins of $0 \mathrm{~h}$ vs. $6 \mathrm{~h}$ PM by western blotting. (B) Validation of the differentially expressed proteins of $6 \mathrm{~h}$ vs. $24 \mathrm{~h}$ PM by western blotting.

Table 7. Validation of the differentially expressed proteins (PKM, TNNT1, COX5A, FIS1, COX4I1, and NDUFB11) by western blotting.

\begin{tabular}{|c|c|c|c|c|c|c|c|c|c|}
\hline \multirow{2}{*}{ Accession } & \multirow{2}{*}{$\begin{array}{c}\text { Gene } \\
\text { Names }\end{array}$} & \multicolumn{2}{|c|}{ TMT (6/0 h) } & \multicolumn{2}{|c|}{ WB (6/0 h) } & \multicolumn{2}{|c|}{ TMT (24/6 h) } & \multicolumn{2}{|c|}{ WB $(24 / 6$ h) } \\
\hline & & FC & $p$ Value & FC & $p$ Value & FC & $p$ Value & FC & $p$ Value \\
\hline A5D984 & PKM & 0.64 & 0 & 0.64 & 0.0056 & & & & \\
\hline Q8MKH6-2 & TNNT1 & 1.47 & $2.15 \times 10^{-33}$ & 1.57 & 0.0024 & & & & \\
\hline P00426 & COX5A & 2.28 & 0.0001 & 1.72 & 0.0017 & & & & \\
\hline Q3T0I5 & FIS1 & & & & & 0.78 & $2.58 \times 10^{-6}$ & 0.65 & 0.0031 \\
\hline P00423 & COX4I1 & & & & & 0.49 & $3.34 \times 10^{-36}$ & 0.61 & 0.0318 \\
\hline Q8HXG5 & NDUFB11 & & & & & 0.87 & 0.0387 & 0.66 & 0.0216 \\
\hline
\end{tabular}

FC indicates the fold change of each differentially expressed protein of 6/0 h PM or 24/6 h PM. TMT: tandem mass tags; WB: western blotting.

\subsection{Metabolic Enzymes}

The changes in metabolic enzymes after slaughter were significantly related to the $\mathrm{pH}$ and meat color in rigor mortis [18,20]. PKM2, DLD, PGAM2, GAPDH, PGM, FBP2, PGK1/2, GPI, ENO3, and TPI1 are all involved in the glycolysis/gluconeogenesis pathway, and were detected in the differential proteins of samples between $0 \mathrm{~h}$ and $6 \mathrm{~h}$ after slaughter in this study. In particular, PKM2 is a key rate-limiting enzyme for glycolysis, catalyzing the transfer of the phosphate group of phosphoenolpyruvate (PEP) to ADP to generate pyruvate and ATP. Higher PKM2 activity is a sign of faster glycolytic metabolism, and various posttranslational modifications (phosphorylation, acetylation, oxidation, and methylation) affect PKM2 activity [28]. Phosphorylation levels of PKM2 at Thr155 were significantly different under different glycolysis rates in ovine muscles [29]. TPI1 is an important glycolytic enzyme that catalyzes the mutual conversion of dihydroxy-acetone phosphate and glyceraldehyde 3-phosphate to provide energy for muscle cells. It has been proposed as a potential biomarker to regulate the development and stability of beef color and $\mathrm{pH}$ during storage [30]. TPI1, including its phosphorylated form, has an effect on the accumulation of lactate and hydrogen protons, which may regulate the level of electrostatic rejection of myofibrillar and filament proteins, thereby affecting the transverse contraction of muscle fibers and lengthening of sarcomeres [5]. In addition to some of the aforementioned proteins, GLO1 and MDH were detected in the pyruvate metabolism pathway. MDH, as a component of the tricarboxylic acid cycle, catalyzed the reaction that regenerates oxaloacetate and was related to the malate-aspartate shuttle system through the mitochondrial membrane to transport reductants. The L-lactate dehydrogenase (LDH)/MDH ratio was used to 
reflect the oxidation level of muscle, and the lower ratio was similar to active oxidative metabolism [31].

\subsection{Mitochondrial Electron Transport Chain}

Protein subunits of complex I (NDUFB6 and NDUFB11), complex II (SDHC and SDHD), complex IV (COX2, COX4I1, COX7C, and COX6C), and complex V (ATP5PO and ATP5MF) of the mitochondrial electron transport chain were detected in the differentially expressed proteins of $24 \mathrm{~h}$ vs. $6 \mathrm{~h}$ PM. The results of Beldarrain et al. [21] suggested that the electrons located between complex III and IV may reduce metmyoglobin. In addition, complex I and complex II regulated the production of NADH, which can be used for the reduction of metmyoglobin through electron transport mediation and enzymatic pathways, thereby affecting meat color [32]. Complex V converted ADP into ATP under the premise of a proton gradient, and the degradation degree of complex $\mathrm{V}$ was directly related to the ATP/ADP homeostasis and affected the stability of meat color [12].

\subsection{Necroptosis and Ferroptosis}

As a new type of cell death mode, necroptosis was first proposed by Degterev et al. [33], and it has the characteristics of both apoptosis and necrosis. Histone H2A type 2-C (H2AC20) and ADP/ATP translocase 1 (SLC25A4) belong to the necroptosis pathway and were detected in the differentially expressed proteins of $24 \mathrm{~h}$ vs. $6 \mathrm{~h}$ PM. SLC25A4 participated in muscle contraction and the calcium-mediated signaling pathway and was abundant in transcription in muscle tissue from two pig breeds [34]. Ferroptosis is a unique iron-dependent form of nonapoptotic cell death caused by the lethal small molecule erastin [35]. VDAC2 and VDAC3 belong to the ferroptosis pathway and were detected in the differentially expressed proteins of $24 \mathrm{~h}$ vs. $6 \mathrm{~h}$ PM. VDAC3 participated in the ferroptosis pathway characterized by iron-dependent lipid peroxidation accumulation and regulated cell death in longissimus dorsi muscle from Xidu black pigs [36]. Ubiquitination of VDAC2/3 by Nedd 4 inhibited ferroptosis in melanoma induced by erastin [37]. Interestingly, SLC25A4 interacted with VDAC2, VDAC3, and NDUFB11 (Figure 3). NDUFB11 participated in mitochondrial function and was associated with apoptosis, indicating that there is a certain correlation between necroptosis, apoptosis, and ferroptosis. Similarly, cytochrome $\mathrm{c}$ was released from the mitochondria into the cytoplasm, leading to the activation of caspases, which can regulate the adenine nucleotide translocator encoded by SLC25A4 and VDAC1/2 [38].

\subsection{Structural Proteins}

The degradation of myofibrillar proteins was related to tenderness, and more fragments than intact structures were observed in tender meat [12]. Some structural proteins identified in this study are known to be related to tenderness, including troponin (TNNC1, TNNT1, and TNNT3), myosin (MYL2, MYL6, MYL6B), and keratin (KRT10, KRT14). Troponin is a heterotrimeric complex composed of troponin $\mathrm{T}$, troponin $\mathrm{I}$, and troponin $\mathrm{C}$ subunits, and plays a central regulatory role in the process of striated muscle contraction [12]. Calcium ions bound to the nh2 domain of troponin C, promoting its interaction with troponin I, leading to its dissociation from actin during muscle contraction. Finally, the troponin I-troponin T complex anchored to the tropomyosin-actin filaments and enhanced actomyosin bonds [21]. Thus, degradation of troponin means that the interacting proteins are destroyed, and the thin filaments in the sarcomeric I band may be broken. The myosin family depended on ATP to participate in muscle contraction and various intracellular functions, such as cell migration and adhesion, signal transduction, intracellular transportation, and localization of macromolecules [11]. Myosin light chains (MYL3 and MYL6B) and regulatory light chain 2 isoforms (MYL2 and MYLPF) were involved in the conversion of muscle to meat, and myosin was a major structural protein related to actin and other contractile proteins. Denaturation of the head of myosin can cause myofibrils to shrink laterally and reduce the WHC [39]. Keratin, as a kind of myofibril protein, was found to 
be a differentially expressed protein between high and low drip loss groups from geese, which was related to WHC [13].

\subsection{Potential Markers during Rigor Mortis}

In addition to the aforementioned proteins, some distinctly different proteins were detected in this study, which may serve as markers that affect the onset and development of rigor mortis. PLN was detected in the differentially expressed proteins of $24 \mathrm{~h}$ vs. $6 \mathrm{~h}$ $\mathrm{PM}$ and participated in some pathways related to calcium ions (calcium signaling pathway and cGMP-PKG signaling pathway) and cardiac contraction and relaxation (adrenergic signaling in cardiomyocytes, thyroid hormone signaling pathway, and dilated cardiomyopathy). PLN controlled the storage level of sarcoplasmic reticulum calcium ions in human hearts and can also act as a regulatory protein for adrenaline. Calcium ion transportation in cells could be affected by mutations of PLN, leading to abnormal myocardial function. Similar to troponin T, PLN is considered a candidate gene for dilated cardiomyopathy because of its role in myofibril calcium sensitivity [40]. In addition, acetyl-coenzyme A acyltransferase (ACAA) includes two subtypes: ACAA1 and ACAA2. ACAA1 was detected in the differentially expressed proteins and mainly involved in physiological and biochemical processes, such as long-chain fatty acid oxidation, bile acid metabolism, and regulation of peroxisome proliferation [41]. The study has shown that increasing ACAA activity can promote peroxisomal fatty acid $\beta$-oxidation, and the accumulation of oxidized polyunsaturated fatty acids is the main cause of ferroptosis [35]. Ankyrin repeat domain 2 (ANKRD2), which belongs to the muscle ankyrin repeat protein (MARP) family, was detected among the differentially expressed proteins. The MARP family plays a key role in the integration of cytoskeletal structure, communication between the sarcoplasm and the nucleus, and stress response [42]. ANKRD2 is a skeletal muscle protein involved in skeletal muscle hypertrophy and located in the I band [43]. The expression profile of porcine ANKRD2 indicated that it may be related to meat quality regulated by muscle fiber type [44]. Moreover, the differential proteins obtained in this study still contained a small number of unknown proteins. These proteins may also play an important role in the rigor mortis of beef, and further research is needed.

\subsection{Meat Quality and Differentially Expressed Proteins}

Glycolysis is an important biochemical pathway affecting meat quality in PM muscles [5]. Glycolytic enzymes, including PKM2 (6 h vs. 0 h), TPI1 (6 h vs. 0 h), ENO3 (6 h vs. $0 \mathrm{~h}$ ) and LDH-B ( $24 \mathrm{~h}$ vs. $6 \mathrm{~h}$ ) were detected in the differential proteins, and the expression levels were basically downregulated to half. Rosenvold et al. revealed that these proteins led to changes in $\mathrm{pH}$ [45]. Consumers regard meat color as the main criterion to judge whether meat is fresh or not. Both hemoglobin and myoglobin are the main pigment proteins, and the key substances that determine meat color [46]. Interestingly, downregulation of hemoglobin in the differential proteins between $6 \mathrm{~h}$ and $24 \mathrm{~h} \mathrm{PM}$ was detected in this study. Moreover, downregulation of NDUFB6, NDUFB11, SDHC, SDHD, COX2, COX4I1, COX7C, COX6C, ATP5PO, and ATP5MF in the differential proteins between $6 \mathrm{~h}$ and $24 \mathrm{~h}$ PM were detected. They can be classified as belonging to complex I, II, IV, and V, which were involved in the mitochondrial electron transport chain. Previous research suggested that the complex can participate in the regulation of myoglobin, thereby affecting the meat color [29,47]. GAPDH, PRDX6, PGM1, and SOD detected in the differential protein between $0 \mathrm{~h}$ and $6 \mathrm{~h}$ were potential predictors of meat color traits, consistent with the results of Wu et al. [48]. Thus, metabolic enzymes, oxidative proteins and mitochondrial electron transport chain complex may be involved in the regulation of meat color at different stages of rigor mortis. Additionally, the change in sarcomere length and MFI may depend primarily on the structural proteins in the differential proteins. Notably, as a new type of cell death mode, ferroptosis has received enthusiastic attention from scientists. VDAC2 and VDAC3 proteins involved in ferroptosis were detected in the differential proteins in this study. ACAA1 was also speculated to participate in ferroptosis because of its function on 
the regulation and accumulation of long-chain fatty acid oxidation. This provides a new perspective for the study of the mechanism of ferroptosis in the regulation of meat quality.

\section{Conclusions}

The quality and protein changes of PM meat used to elucidate the biochemical mechanism of rigor mortis were explored. The beef meat quality including $\mathrm{pH}$, meat color, total sulfhydryl content, sarcomere length, and MFI changed significantly within $24 \mathrm{~h}$ after slaughter. A total of 147 differentially expressed proteins involved in a certain number of signaling pathways were analyzed using TMT quantitative proteomics. Several proteins that may play a key role in rigor mortis were also proposed. Further verification of differential proteins and new strategies are needed to supplement the presented theories in the development of rigor mortis.

Supplementary Materials: The following supporting information can be downloaded at: https: / / www.mdpi.com/article/10.3390/foods11020217/s1, Table S1: differentially expressed proteins were identified between $6 \mathrm{~h}$ and $0 \mathrm{~h}$ PM; Table S2: differentially expressed proteins were identified between $24 \mathrm{~h}$ and $6 \mathrm{~h}$ PM; Table S3: GO analyses of the differentially expressed proteins between $6 \mathrm{~h}$ and $0 \mathrm{~h}$ PM; Table S4: GO analyses of the differentially expressed proteins between $24 \mathrm{~h}$ and $6 \mathrm{~h} \mathrm{PM}$; Table S5: KEGG pathway analyses of the differentially expressed proteins between $6 \mathrm{~h}$ and $0 \mathrm{~h}$ PM; Table S6: KEGG pathway analyses of the differentially expressed proteins between $24 \mathrm{~h}$ and $6 \mathrm{~h}$ PM.

Author Contributions: Conceptualization, Z.D. and F.H.; methodology, Q.W.; software, C.L.; validation, Z.D., Q.W. and C.L.; formal analysis, Z.D.; investigation, H.Z.; resources, F.H.; data curation, F.H.; writing —original draft preparation, Z.D.; writing—review and editing, F.H.; visualization, Z.D.; supervision, F.H.; project administration, H.Z.; funding acquisition, F.H. All authors have read and agreed to the published version of the manuscript.

Funding: This research received no external funding.

Institutional Review Board Statement: The protocol was approved by National Standards of China (protocol code, GB/T 17237-2008; date: 2008) and the Animal Care and Ethics Committee of Chinese Academy of Agricultural Sciences (IAS20160616; date: 2016, Beijing, China).

Informed Consent Statement: The study did not involve humans.

Data Availability Statement: The study did not report any data.

Acknowledgments: This research was funded by the National Natural Science Foundation of China (Grant No. 32072244) and Key Scientific and Technological Projects of Xinjiang Production and Construction Corps (Grant No. 2020AB012).

Conflicts of Interest: The authors declare no conflict of interest.

\section{References}

1. Hertzman, C.; Olsson, U.; Tornberg, E. The influence of high temperature, type of muscle and electrical stimulation on the course of rigor, ageing and tenderness of beef muscles. Meat Sci. 1993, 35, 119-141. [CrossRef]

2. Ouali, A.; Herrera-Mendez, C.; Coulis, G.; Becila, S.; Boudjellal, A.; Aubry, L. Revisiting the conversion of muscle into meat and the underlying mechanisms. Meat Sci. 2006, 74, 44-58. [CrossRef]

3. Li, C.; Shi, P.; Chang, X.; Xu, X.; Zhou, G. Tracing processes of rigor mortis and subsequent resolution of chicken breast muscle using a texture analyzer. J. Food Eng. 2010, 99, 388-391. [CrossRef]

4. Matarneh, S.; England, E.; Scheffler, T.; Gerrard, D. The conversion of muscle to meat. In Lawrie's Meat Science (eight edition); Woodhead Publishing Series in Food Science, Technology and Nutrition; Elsevier: Amsterdam, The Netherlands, 2017; pp. 159-185.

5. Huang, C.; Hou, C.; Ijaz, M.; Yan, T.; Li, X.; Li, Y.; Zhang, D. Proteomics discovery of protein biomarkers linked to meat quality traits in post-mortem muscles: Current trends and future prospects: A review. Trends Food Sci. Technol. 2020, 105, 416-432. [CrossRef]

6. Paredi, G.; Raboni, S.; Bendixen, E.; Almeida, A.; Mozzarelli, A. “Muscle to meat” molecular events and technological transformations: The proteomics insight. J. Proteom. 2012, 75, 4275-4289. [CrossRef]

7. Poleti, M.D.; Moncau, C.T.; Silva-Vignato, B.; Rosa, A.F.; Lobo, A.R.; Cataldi, T.R.; Negrão, J.A.; Silva, S.L.; Eler, J.P.; Balieiro, J.C.D.C. Label-free quantitative proteomic analysis reveals muscle contraction and metabolism proteins linked to ultimate $\mathrm{pH}$ in bovine skeletal muscle. Meat Sci. 2018, 145, 209-219. [CrossRef] 
8. Bendixen, E. The use of proteomics in meat science. Meat Sci. 2005, 71, 138-149. [CrossRef]

9. Gagaoua, M.; Bonnet, M.; Ellies-Oury, M.P.; De Koning, L.; Picard, B. Reverse phase protein arrays for the identification/validation of biomarkers of beef texture and their use for early classification of carcasses. Food Chem. 2018, 250, 245-252. [CrossRef] [PubMed]

10. Wu, W.; Yu, Q.; Fu, Y.; Tian, X.; Jia, F.; Li, X.; Dai, R. Towards muscle-specific meat color stability of Chinese Luxi yellow cattle: A proteomic insight into post-mortem storage. J. Proteom. 2016, 147, 108-118. [CrossRef]

11. Yu, Q.; Wu, W.; Tian, X.; Hou, M.; Dai, R.; Li, X. Unraveling proteome changes of Holstein beef M. semitendinosus and its relationship to meat discoloration during post-mortem storage analyzed by label-free mass spectrometry. J. Proteom. 2017, 154, 85-93. [CrossRef]

12. Ding, Z.; Wei, Q.; Zhang, C.; Zhang, H.; Huang, F. Influence of oxidation on Heat Shock Protein 27 translocation, caspase-3 and calpain activities and myofibrils degradation in postmortem beef muscles. Food Chem. 2020, 340, 127914. [CrossRef]

13. Zhang, M.; Wang, D.; Xu, X.; Xu, W. Comparative proteomic analysis of proteins associated with water holding capacity in goose muscles. Food Res. Int. 2018, 116, 354-361. [CrossRef] [PubMed]

14. Malheiros, J.; Braga, C.; Grove, R.; Ribeiro, F.; Calkins, C.; Adamec, J.; Chardulo, L. Influence of oxidative damage to proteins on meat tenderness using a proteomics approach. Meat Sci. 2019, 148, 64-71. [CrossRef]

15. Gagaoua, M.; Bonnet, M.; De Koning, L.; Picard, B. Reverse phase protein array for the quantification and validation of protein biomarkers of beef qualities: The case of meat color from Charolais breed. Meat Sci. 2018, 145, 308-319. [CrossRef] [PubMed]

16. Sentandreu, M.A.; Coulis, G.; Ouali, A. Role of muscle endopeptidases and their inhibitors in meat tenderness. Trends Food Sci. Technol. 2002, 13, 400-421. [CrossRef]

17. Zhang, M.; Wang, D.; Huang, W.; Liu, F.; Zhu, Y.; Xu, W.; Cao, J. Apoptosis during postmortem conditioning and its relationship to duck meat quality. Food Chem. 2013, 138, 96-100. [CrossRef] [PubMed]

18. He, J.; Xia, C.; He, Y.; Pan, D.; Cao, J.; Sun, Y.; Zeng, X. Proteomic responses to oxidative damage in meat from ducks exposed to heat stress. Food Chem. 2019, 295, 129-137. [CrossRef]

19. Alvarado, C.Z.; Sams, A.R. Rigor mortis development in Turkey breast muscle and the effect of electrical stunning. Poult. Sci. 2000, 79, 1694-1698. [CrossRef] [PubMed]

20. Li, S.; Yu, Q.; Han, L.; Zhang, Y.; Tian, X.; Zhao, S. Effects of proteome changes on the tenderness of yak rumen smooth muscle during postmortem storage based on the label-free mass spectrometry. Food Res. Int. 2019, 116, 1336-1343. [CrossRef]

21. Beldarrain, L.R.; Aldai, N.; Picard, B.; Sentandreu, E.; Navarro, J.L.; Sentandreu, M.A. Use of liquid isoelectric focusing (OFFGEL) on the discovery of meat tenderness biomarkers. J. Proteom. 2018, 183, 25-33. [CrossRef]

22. Zhang, Y.; Zhang, B.; Huang, Y.; Chen, L.; Bao, P.; Fang, H.; Zhou, C. L-arginine and L-lysine degrade troponin-T, and L-arginine dissociates actomyosin: Their roles in improving the tenderness of chicken breast. Food Chem. 2020, 318, 126516. [CrossRef]

23. Merino, F.; Pospich, S.; Funk, J.; Wagner, T.; Raunser, S. Structural transitions of F-actin upon ATP hydrolysis at near-atomic resolution revealed by cryo-EM. Nat. Struct. Mol. Biol. 2018, 25, 528-537. [CrossRef] [PubMed]

24. Wang, Y.; Li, X.; Li, Z.; Li, M.; Zhu, J.; Zhang, D. Changes in degradation and phosphorylation level of titin in three ovine muscles during postmortem. Int. J. Food Sci. Technol. 2018, 53, 913-920. [CrossRef]

25. Yu, L.H.; Lee, E.S.; Jeong, J.Y.; Choi, J.H.; Kim, C.J. Effects of Post-mortem Temperature on the Physicochemical Properties of Hot-boned Chicken Breast Muscles. Food Sci. Anim. Resour. 2009, 29, 55-61. [CrossRef]

26. Ertbjerg, P.; Puolanne, E. Muscle structure, sarcomere length and influences on meat quality: A review. Meat Sci. 2017, 132, 139-152. [CrossRef] [PubMed]

27. Cornforth, D.; Pearson, A.; Merkel, R. Relationship of mitochondria and sarcoplasmic reticulum to cold shortening. Meat Sci. 1980, 4, 103-121. [CrossRef]

28. Alquraishi, M.; Puckett, D.L.; Alani, D.S.; Humidat, A.S.; Bettaieb, A. Pyruvate kinase M2: A simple molecule with complex functions. Free Radic. Biol. Med. 2019, 143, 176-192. [CrossRef]

29. Marsh, B.B. Rigor mortis in beef. J. Sci. Food Agric. 2010, 5, 70-75. [CrossRef]

30. Gagaoua, M.; Couvreur, S.; Bec, G.L.; Aminot, G.; Picard, B. Associations among protein biomarkers and $\mathrm{pH}$ and color traits in longissimus thoracis and rectus abdominis muscles in protected designation of origin maine-Anjou cull cows. J. Agric. Food Chem. 2017, 65, 3569-3580. [CrossRef] [PubMed]

31. Yu, Q.; Feng, D.; Xiao, J.; Wu, F.; Zuo, J.J. Studies on meat color, myoglobin content, enzyme activities, and genes associated with oxidative potential of pigs slaughtered at different growth stages. Asian-Australas. J. Anim. Sci. 2017, 30, 1739-1750. [CrossRef]

32. Belskie, K.M.; Buiten, C.; Ramanathan, R.; Mancini, R.A. Reverse electron transport effects on NADH formation and metmyoglobin reduction. Meat Sci. 2015, 105, 89-92. [CrossRef] [PubMed]

33. Degterev, A.; Huang, Z.; Boyce, M.; Li, Y.; Jagtap, P.; Mizushima, N.; Cuny, G.D.; Mitchison, T.J.; Moskowitz, M.A.; Yuan, J Chemical inhibitor of nonapoptotic cell death with therapeutic potential for ischemic brain injury. Nat. Chem. Biol. 2005, 1, 112-119. [CrossRef] [PubMed]

34. Ropka-Molik, K.; Żukowski, K.; Eckert, R.; Gurgul, A.; Piórkowska, K.; Oczkowicz, M. Comprehensive analysis of the whole transcriptomes from two different pig breeds using RNA-Seq method. Anim. Genet. 2015, 45, 674-684. [CrossRef] [PubMed]

35. Dixon, S.J.; Lemberg, K.M.; Lamprecht, M.R.; Skouta, R.; Zaitsev, E.M. Ferroptosis: An Iron-Dependent Form of Nonapoptotic Cell Death. Cell 2012, 149, 1060-1072. [CrossRef] 
36. Zhou, J.; Zhang, Y.; Wu, J.; Qiao, M.; Mei, S. Proteomic and lipidomic analyses reveal saturated fatty acids, phosphatidylinositol, phosphatidylserine, and associated proteins contributing to intramuscular fat deposition. J. Proteom. 2021, 241, 104235. [CrossRef] [PubMed]

37. Yang, Y.; Luo, M.; Zhang, K.; Zhang, J.; Chen, W. Nedd4 ubiquitylates VDAC2/3 to suppress erastin-induced ferroptosis in melanoma. Nat. Commun. 2020, 11, 433. [CrossRef]

38. Siragusa, M.; Sessa, W.C. Telmisartan exerts pleiotropic effects in endothelial cells and promotes endothelial cell quiescence and survival. Arter. Thromb. Vasc. Biol. 2013, 33, 1852-1860. [CrossRef]

39. Zuo, H.; Han, L.; Yu, Q.; Niu, K.; Zhao, S.; Shi, H. Proteome changes on water-holding capacity of yak longissimus lumborum during postmortem aging. Meat Sci. 2016, 121, 409-419. [CrossRef]

40. Gustafson, P.; Lin, K.C.; Xu, J.; Kamara, D.; Geng, T.; Gyenai, K.; Reed, K.M.; Smith, E.J. DNA sequence and haplotype variation in two candidate genes for dilated cardiomyopathy in the turkey Meleagris gallopavo. Genome 2015, 50, 463-469.

41. Krishnamoorthy, S.; Jin, R.; Cai, Y.; Maddipati, K.R.; Nie, D.; Pagès, G.; Tucker, S.C.; Honn, K.V. 12-Lipoxygenase and the regulation of hypoxia-inducible factor in prostate cancer cells. Exp. Cell Res. 2010, 316, 1706-1715. [CrossRef]

42. Wang, L.; Lei, M.; Xiong, Y. Molecular Characterization and Different Expression Patterns of the Muscle Ankyrin Repeat Protein (MARP) Family During Porcine Skeletal Muscle Development in vitro and in vivo. Anim. Biotechnol. 2011, 22, 87-99. [CrossRef] [PubMed]

43. Pallavicini, A.; Kojić, S.; Bean, C.; Vainzof, M.; Salamon, M.; Ievolella, C.; Bortoletto, G.; Pacchioni, B.; Zatz, M.; Lanfranchi, G. Characterization of Human Skeletal Muscle Ankrd2. Biochem. Biophys. Res. Commun. 2001, 285, 378-386. [CrossRef] [PubMed]

44. Sun, L.; Dong, X.; Fan, B.; Liu, B. The Association of ANKRD2 with Loin Depth and Muscle Firmness in Pigs. J. Anim. Vet. Adv. 2011, 10, 1462-1468. [CrossRef]

45. Rosenvold, K.; Petersen, J.; Laerke, H.; Jensen, S.; Therkildsen, M.; Karlsson, A.; Moller, H.; Andersen, H. Muscle glycogen stores and meat quality as affected by strategic finishing feeding of slaughter pigs. J. Anim. Sci. 2001, 79, 382-391. [CrossRef] [PubMed]

46. Suman, S.; Joseph, P. Myoglobin chemistry and meat color. Annu. Rev. Food Sci. Technol. 2013, 4, 79-99. [CrossRef] [PubMed]

47. Chen, L.; Li, Z.; Everaert, N.; Lametsch, R.; Zhang, D. Quantitative phosphoproteomic analysis of ovine muscle with different postmortem glycolytic rates. Food Chem. 2019, 280, 203-209. [PubMed]

48. Wu, W.; Gao, X.; Dai, Y.; Fu, Y.; Li, X.; Dai, R. Post-mortem changes in sarcoplasmic proteome and its relationship to meat color traits in M. semitendinosus of Chinese Luxi yellow cattle. Food Res. Int. 2015, 72, 98-105. [CrossRef] 